\title{
Tente, invente, mas faça o telespectador ser da gente: Globo e Record, a disputa de quase duas décadas
}

\author{
Try, create, but make the viewer be ours: \\ Globo and Record, the dispute of two decades
}

\author{
André Kron Marques Zapani
}

Professor do Colégio Militar de Curitiba, jornalista, Mestrando do curso de Comunicação e Linguagens da Universidade Tuiuti do Paraná (UTP/PR), membro do Grupo de Pesquisa JOR XXI, Curitiba, PR - Brasil, e-mail: andrekron@ig.com.br

\section{Resumo}

A disputa midiática televisiva vem ganhando a cada dia novos capítulos na batalha pela conquista da audiência. Este embate, entre líder e vice-líder, que se caracteriza pelos antagonismos desde a fundação à consolidação das marcas, tem em seu cerne predicados litúrgicos do sagrado/profano. A contenda se iniciou há quase 20 anos e hoje integra um processo tautológico temporal cíclico que atualmente vive no ápice de sua visibilidade e de sua espetacularidade. Este artigo busca analisar sinteticamente as causas históricas, políticas e sociais desta rivalidade, tomando como exemplo uma discussão recente, ao vivo, entre repórteres de ambas emissoras em programa diário de televisão aberta, fazendo uma comparação da disputa midiática pela audiência com a sociedade contemporânea do hiperespetáculo e com a produção noticiosa jornalística.

Palavras-chave: Globo. Record. Audiência. Disputa midiática. Sociedade do hiperespetáculo.

\begin{abstract}
The telecasting media dispute has gained new chapters in the battle of audience. The struggle between leader and vice-leader channels, characterized by antagonisms in their foundation to the consolidation of their brands, has in its core sacred/ profane liturgical predicates. The fight began almost 20 years ago and it is part of a tautological temporal cyclic process that is nowadays at the apex of its visibility and spectacularly. This article tries to analyze briefly historical, political and social causes of the rivalry, taking the example of a recent live discussion between two reporters of both channels during a daily program, on open TV, aiming to compare the media dispute for audience, the contemporary society of byper-spectacle and the broadcasting production.
\end{abstract}

Keywords: Globo. Record. Hearing. Dispute media. Society of byper-spectacle. 


\section{Introdução}

O Brasil, a partir de meados da década de 1980, viveu novas conjunturas sociais, econômicas, políticas e culturais. Foi o período de transição para as renovadas ideologias democráticas, do reaparecimento gradual de uma sociedade polifônica e do direito mais amplo da expressão popular, antes cerceados pelos prévios governos. Com a promulgação da Constituição Federal de 1988 (BRASIL, 1988), tornou-se oficial o veto a qualquer dispositivo que limitasse a liberdade de informação jornalística.

Foi também época do surgimento no Brasil $\mathrm{da}$ internet e de tecnologias digitais, da maturidade das telecomunicações e do retorno do pluripartidarismo. Tempos de manifestações inéditas de fé e do surgimento de novos grupos religiosos (neopentecostais), difusores de teologia e doutrina díspares com a tradição existente. Período de solidificação dos poderes midiáticos da família Marinho, do aparecimento de novos proprietários no mercado (Edir Macedo, da Rede Record), da extinção da Rede Manchete e do surgimento da Rede TV!, bem como da segmentação e customização da programação para públicos definidos e a busca incessante pelos índices de audiência, condição sine qua non para a sobrevivência das mídias de massa

Este artigo tem o objetivo de analisar a disputa midiática entre as emissoras líder e vice-líder em audiência televisiva aberta, Globo e Record, responsáveis parciais pela evolução no mercado da comunicação, mas que são protagonistas de reiteradas acusações mútuas de improbidades financeiras, consolidação patrimonial ilegal, aliciamento de profissionais, denúncias infundadas, entre outras.

\section{A consolidação dos reinados}

De acordo com Martins (1990 apud MARIANO, 2005, p. 28), a religião protestante, fundada pelo monge Martinho Lutero no século XVI, divide-se em três grandes ondas: puritana, metodista e pentecostal. Esta última teve sua origem em 1901, nos EUA, e encontrou na América Latina, no sul da África e no sudeste asiático terreno fértil para a difusão de suas ideias. Em pouco tempo, cerca de sete décadas, teve grande expansão geográfica e aumento no número de seguidores, estopim para o processo de segmentação e sincretismo religioso contemporâneo nacional.

Segundo Mariano (2005), a cronologia da religião pentecostal no País tem início com a fundação das igrejas da Congregação Cristã (1910) e da Assembleia de Deus (1911). Na década de 1950, novas doutrinas e templos se estabeleceram com a chegada de imigrantes europeus e americanos. Foi o caso das Igrejas do Evangelho Quadrangular (1951), Brasil para Cristo (1955), Nova Vida (1960), Deus é Amor (1962), entre outras menores que tiveram a cidade de São Paulo como sede. A partir do fim da década de 1970, segmentos religiosos dissidentes dessas igrejas ganharam autonomia, criando seus próprios templos e desenvolvendo táticas proselitistas excêntricas à época. São elas: Igreja Universal do Reino de Deus (1977), Igreja Internacional da Graça de Deus (1980), Igreja Apostólica Renascer em Cristo (1986) e Igreja Mundial do Poder de Deus (1998).

Embora entre as igrejas neopentecostais não haja homogeneização teológica e litúrgica, características em comum podem, quase sempre, seridentificadas: difusão da Teologia da Prosperidade (apego à fruição e ao consumo material nesta vida e neste mundo) como célula mater da doutrina; "guerra religiosa" entre o bem e o mal (exorcismos, liturgia que já existia na fase histórica, mas que ganhou mais difusão atualmente); combate às doutrinas afro-descendentes, indígenas e espíritas; fidelização do dízimo como principal sacrifício e motivo para recompensas e bênçãos futuras; visão empreendedora e mercadológica da igreja como instituição religiosa; liderança centralizada, militância política e utilização dos meios de comunicação de massa (Tabela 1) (MARIANO, 2005).

As igrejas neopentecostais tinham como público-alvo inicial as classes sociais mais carentes, principalmente nas duas primeiras décadas, mas vêm ganhando novos rumos, segundo Valle (1998, p. 198):

[...] estão alcançando grande êxito junto às massas abandonadas do catolicismo popular. O solo do sucesso dessas igrejas é o espaço urbano plural e privatizado; são as carências de vários tipos, vividas pelo povo; as necessidades formalmente religiosas de todo ser humano.

O quadro atual passa a incluir cidadãos de classes mais elevadas, graças à disseminação da Teologia da Prosperidade, que "serve de legitimação 
religiosa aos ricos que almejam a "paz de espírito"” (FERRARI, 2007, p. 91). Possui o fulcro teológico "da satisfação dos desejos no consumo, permitindo usufruir não só de bens necessários, mas também de produtos supérfluos, experimentando a sensação dos prazeres do eterno no instante" (FERRARI, 2007).

A fé tornou-se produto de marketing, com o propósito de atender à demanda do mercado religioso, que a cada dia ganha novos números no efetivo total de fiéis. Os evangélicos pentecostais (nas três fases), segundo o IBGE (2000), eram em número de 26.184.941 fiéis $(6,48 \%$ da população brasileira) e os católicos, de 124.980 .132 (73\%). No entanto, conforme pesquisa realizada pela Datafolha (2007), os católicos passaram a ser $64 \%$ e os pentecostais $17 \%$.

Este panorama contemporâneo da fé como produto midiático iniciou-se quando, “em 1983, o pastor batista Nilson Fanini obteve do então presidente João Figueiredo a concessão do canal 13, da extinta TV Rio" (ASSMANN, 1986, apud ALMEIDA, 2009, p. 136), mas a gênese do sucesso atual se deu em novembro de 1989, quando Edir Macedo
Bezerra, bispo e líder da Igreja Universal do Reino de Deus, segundo Troca (1989), por intermédio do empresário Alberto Luiz Haddad, comprou a Rede Record de Rádio e Televisão, por 45 milhões de reais, dos grupos do proprietário do Sistema Brasileiro de Telecomunicação (SBT), Sílvio Santos, e do fundador da emissora, Paulo Machado de Carvalho.

Sob nova administração, a Record inicia uma fase de renovação. A interligação ao sistema da Empresa Brasileira de Telecomunicações (Embratel) foi determinante para a expansão de sua programação, tornando-a uma emissora de rede nacional. Investimentos foram feitos na área tecnológica, em produções próprias (novelas, reality shows), em esporte e em jornalismo de qualidade. Além disso, passou a investir na compra de produções estrangeiras (filmes e séries) e "foi adquirindo e se filiando às antigas emissoras como a TV Sociedade (BH), TV Cultura (SC), TV Vale do Itajaí (SC), TV Xanxerê (SC), além de colaborar na reequipagem das TV Capital (DF), TV MS (MS) e TV O Norte (PB) e TV Rio (RJ)" (AMORIM, 1999, p. 40), (Tabela 1).

Tabela 1 - Inserções televisivas das igrejas neopentecostais / setembro 2009

\begin{tabular}{|c|c|c|c|}
\hline Igrejas & Ano & Televisão & Horários \\
\hline \multirow{4}{*}{$\begin{array}{l}\text { Igreja Universal do } \\
\text { Reino de Deus }\end{array}$} & \multirow{4}{*}{1977} & Rede Record (locação de horário) & Madrugadas diárias \\
\hline & & Rede TV! (locação de horário) & \multirow[t]{3}{*}{$5,5 \mathrm{~h}$ semanais } \\
\hline & & Record News (propriedade de pastores) & \\
\hline & & Rede Família (propriedade de pastores) & \\
\hline \multirow{5}{*}{$\begin{array}{l}\text { Igreja Internacional da } \\
\text { Graça de Deus }\end{array}$} & \multirow{5}{*}{1980} & CNT (locação) & 36h semanais \\
\hline & & Rede TV! (locação de horários) & $12 \mathrm{~h}$ semanais \\
\hline & & Band (locação de horários) & \multirow[t]{2}{*}{ 6h semanais } \\
\hline & & Record (locação) & \\
\hline & & $\begin{array}{l}\text { Rede Internacional de Televisão (RIT) } \\
\text { Satélite (proprietária) }\end{array}$ & 24h diárias de seg. a dom. \\
\hline $\begin{array}{l}\text { Igreja Apostólica } \\
\text { Renascer em Cristo }\end{array}$ & 1986 & Rede Gospel de Televisão/UHF (proprietária) & 24h diárias de seg. a dom \\
\hline \multirow{4}{*}{$\begin{array}{l}\text { Igreja Mundial do } \\
\text { Poder de Deus }\end{array}$} & \multirow{4}{*}{1998} & Rede 21/UHF/, Bandeirantes (arrendamento) & \\
\hline & & Rede Gênese/UHF (locação) & $31 \mathrm{~h}$ semanais \\
\hline & & CNT (locação de horários) & $13 \mathrm{~h}$ semanais \\
\hline & & Rede TV! (locação de horários) & $17,5 \mathrm{~h}$ semanais \\
\hline $\begin{array}{l}\text { Igreja Evangélica Bola } \\
\text { de Neve }\end{array}$ & 1999 & Rede TV (locação de horários) & $0,5 \mathrm{~h}$ no domingo \\
\hline
\end{tabular}

Fonte: Site das emissoras.

Rev. Estud. Comun., Curitiba, v. 11, n. 24, p. 39-47, jan./abr. 2010 
No entanto, a venda da emissora não teve muita repercussão nas mídias, fato que pode ser analisado por sua limitada influência no mercado midiático, pela cobertura regional e restrita às cidades de São Paulo, Franca e Ribeirão Preto - tanto que tinha os slogans "Novamente crescendo com São Paulo" (1976-1980) e "Record, ligada em São Paulo" (1986-1990) - e pela baixa audiência que adquiria (o pico não passava de cinco pontos no Ibope).

Passado o processo eleitoral e de transferência de propriedade, a Record sofreu diversas alterações na sua grade de programação (deslocou os programas evangélicos para a madrugada, reduziu as cenas de ritos de exorcismos nos telecultos, limitou os pedidos de dízimos aos templos e reduziu a difusão de filmes violentos e com cenas eróticas), contratou profissionais renomados, e outros que viriam a ser, dos ramos artístico e jornalístico (Ana Maria Braga, Ratinho, Luis Datena, Raul Gil, Eliana, Roberto Cabrini, Marcos Hummel, Ana Hickmann, Gugu Liberato, Tom Cavalcante, Roberto Justus, diretores e produtores) e construiu uma sede de dimensões maiores no bairro paulistano da Barra Funda. A partir de 2006 grandes investimentos financeiros foram realizados para se obter um crescimento no índice de audiência - só na teledramaturgia foram investidos $\mathrm{R} \$$ 300 milhões (MARTHE, 2007). Cerca de 40\% de seus técnicos vieram da concorrente. Artistas, diretores e produtores foram atraídos por salários bem mais altos, até 680\% maiores. $\mathrm{Na}$ área jornalística, que passou a ter o Jornal da Record como o telejornal "genérico" e possível rival do Jornal Nacional, foram injetados R\$ 50 milhões e 250 novos profissionais, sem contar que a criação do primeiro canal de notícias da TV aberta (Record Newss). Por quase R $\$ 1,5$ bilhão, a emissora adquiriu o direito de transmissão das Olimpíadas de Inverno, em Vancouver (2010), das Olimpíadas de Verão, em Londres (2012), da Copa do Mundo de futebol na África do Sul e no Brasil (2010 e 2014) e dos campeonatos de futebol paulista e brasileiro (2008).

A Record registrou um crescimento expressivo nos últimos anos. Em janeiro de 2006, segundo a reportagem "Record estaciona e não assusta Globo" (2008), a primeira tinha média diária de 5,3 pontos na Grande São Paulo, contra 7,7 do SBT e 20,7 da Globo. Em 2007, fechou com 7,2 pontos, um crescimento de $18 \%$ com relação a 2006 , e deixou o SBT para trás $(6,4)$. No início de 2008 , seu crescimento foi maior ainda. Em abril, impulsionada pelo caso Isabella, atingiu média de 9,8 pontos, $11,4 \%$ a mais do que no mês anterior. Sua distância para o SBT era de 3,8 pontos. Para a Globo $(18,4)$, era de 8,6, quase metade da do início de 2006, mas ainda bem grande. Números que a fizeram alterar o slogan de "A caminho da liderança" (2006-2008) para "TV de primeira" (desde 2008).

Em pesquisa ${ }^{1}$ realizada no ano de 2009 , pelo Grupo Ibope, na cidade de São Paulo, pode-se comprovar ainda a liderança isolada da "Vênus Platinada" (média anual de 30,9 pontos), mas não com a larga margem presente nas décadas de 70 e 80 , "cujos picos de audiência chegaram a 78 pontos - novela Roque Santeiro (1985-86) e a 75 pontos - novela Locomotivas (1977)" (BORELLI; PRIOLLI, 2000, p. 28).

Com o decorrer dos anos, a política religiosa adotada pela Record para captação de novos fiéistelespectadores, haja vista que a Igreja Universal do Reino de Deus é um dos grandes investidores, foi tomando novos rumos pelas diversas acusações e divergências religiosas entre emissoras e entidades religiosas. O retraimento no número de inserções (exclusivo nos horários da madrugada) e no conteúdo de seus programas religiosos (redução nos cultos de exorcismos e combate à iconolatria) Despertar da Fé, $25^{a}$ Hora e Palavras da Vida foram ficando evidentes.

A década de 1960, do ponto de vista econômico, pode ser caracterizada predominantemente como o período de abertura econômica e de entrada de capital estrangeiro nas relações financeiras nacionais. Investimentos externos são injetados em empresas de comunicação, via publicidades feitas por agências estrangeiras. Diversos empresários brasileiros do ramo foram "convidados" por investidores internacionais a fazer parcerias midiáticas, embora tais contratos jurídicos não fossem legal, segundo a Constituição Federal de 1946:

Art.160 - É vedada a propriedade de empresas jornalísticas, sejam políticas ou simplesmente noticiosas, assim como a de radiofusão, a sociedades anônimas por ações ao portador e aos estrangeiros. Nem esses, nem pessoas jurídicas, excetuados os partidos nacionais, poderão ser acionistas de sociedades anônimas proprietárias dessas empresas. A brasileiros (art. 129, $\mathrm{n}^{\circ} \mathrm{s}$ I e II) caberá, exclusivamente, a responsabilidade principal delas e a sua orientação intelectual e administrativa (HERZ, 1989, p. 229).

\footnotetext{
1 A pesquisa foi realizada diariamente, das 6 h às 5h59, contemplando universos de 5.728 .442 domicílios e 17.701 .760 indivíduos. Um ponto de audiência corresponde a $1 \%$ desses respectivos universos.
} 
No entanto, desde a década de 1940, relações financeiras ilegais já eram realizadas. A revista Seleçôes Reader's Digest, de origem norte-americana, já punha à venda seus exemplares, que eram difusores da ideologia daquele país, ora participante da Segunda Guerra Mundial.

Essa ilegalidade logo se estendeu para a mídia televisiva. Segundo João Calmon (1966, apud HERZ, 1989), o convite do grupo americano TimeLife para atuar em território nacional foi negado por Julio Mesquita Filho, dono do jornal O Estado de São Paulo. No entanto, foi aceito pelas organizações Globo (jornal O Globo, editora Rio Gráfica eRádio Globo), do empresário Roberto Marinho, que na época já "cedia espaços para a publicidade estrangeira para mover campanhas, por exemplo contra a nacionalização do petróleo" (SODRÉ, 1977, p. 460-467 apud HERZ, 1989, p. 93).

Em 1962, consolida-se a parceria Marinho/ Time-Life, originando a TV Globo Ltda, que ficou vinculada à Rádio Globo e somente iria ao ar em 1965.

Durante o governo militar, iniciado em 1964, as concessões para funcionamento dos canais de TV, prerrogativas inerentes do Poder Executivo, serviram como moeda de troca entre o governo, que necessitava dos meios massivos para projetar nacionalmente sua ideologia, e o empresário, "parceiro do Estado" que adquiriria muitas vezes outro veículo e ampliaria seu lucro e seu poder simbólico. Além disso, o governo federal era o maior anunciante e um dos grandes investidores financeiros das empresas de comunicação, o que levou a ter controle direto/indireto (conteúdo dos programas) das diversas mídias, que viviam período de evolução tecnológica e patrimonial. No mesmo período, assiste-se a uma expansão de audiência. Segundo Mattos (2008, p. 29), a venda de aparelhos de televisão em preto e branco aumentou $24,1 \%$ entre 1967 e 1979, enquanto a dos em cores tiveram um acréscimo de $1.479 \%$, entre 1972 e 1979, Tabela 2.
No fim dos anos 1970, a Globo, já sem a parceria, possuía a liderança de audiência, detinha elevado conhecimento técnico na produção de televisão, possuía equipamentos mais desenvolvidos, além de ter direcionado sua programação para a população de menor poder socioeconômico.

A Rede Globo hoje é um grande pool de empresas do ramo das comunicações (jornal, rádio, TV aberta, TV fechada, portal de internet) que hoje está entre as cinco maiores do mundo, vende diversas produções artísticas para o exterior, possui o segundo jornal de maior tiragem nacional, é a líder de audiência, quase de maneira integral, e desenvolveu um padrão de excelência gerencial e técnica (Padrão Globo) que é tomado com referência por diversas empresas de comunicação nacionais e internacionais.

\section{A gente se vê no espetáculo midiático da vida}

Com a aquisição da Record por Edir Macedo, a emissora/igreja deixou de ser exclusivamente notícia e passou a ser produtora e difusora de informação. Independentemente da baixa audiência na primeira década, a demonstração de poder já era evidente. A emissora possuía um meio massivo para atacar, difundir sua liturgia proselitista e se defender de seus concorrentes. A audiência paulatinamente foi sendo conquistada e seus concorrentes superados Band, SBT e Rede TV! -, resultado da renovação na programação e da fidelidade de seus seguidores religiosos. Embora Globo e Record tenham divergências em seus mundos imaginários e grande disparidade ideológica, as atitudes tomadas pelas entidades midiáticas em busca do eldorado ou da mítica Pasárgada fazem-nas convergir para o Centro do Mundo, que segundo definição de Eliade (2008, p. 60), "informa não somente os países, as cidades, os templos e os

Tabela 2 - Número de concessões outorgadas para funcionamento de emissoras de TV / ano

\begin{tabular}{lll}
\hline Período & Presidente & Concessões outorgadas \\
\hline $1956-1964$ & $\begin{array}{l}\text { Juscelino Kubitschek (1956-1961) } \\
\text { Jânio Quadros (1961) }\end{array}$ & 14 \\
& $\begin{array}{l}\text { João Goulart (1961-1964) } \\
\text { Gen. Castelo Branco (1964-1967) }\end{array}$ & 23 \\
$1964-1969$ & Gen. Costa e Silva (1967-1969) & 20 \\
$1969-1974$ & Gen. Emílio G. Médici & 46 \\
$1979-1985$ & Gen. João Figueiredo & \\
\hline
\end{tabular}

Fonte: MATTOS, 2008, p. 121. 
palácios, mas também a modesta habitação humana, seja a tenda do caçador nômade, o yourte dos pastores, a casa dos agricultores sedentários", mas que no contexto atual tem uma denotação profana e que se traduz em um produto de posse fugaz - a audiência.

O sumário dos embates midiáticos, em sua introdução, faz constar o episódio da prisão de Macedo, sob acusação de charlatanismo e curandeirismo, em maio de 1992. Nos capítulos seguintes, o embate se formalizou pela concepção de McLuhan, haja vista que os próprios meios foram a mensagem para a consolidação do embate midiático.

O discurso tautológico dos reiterados ataques mútuos se fazem presentes em um contexto lato da mídia. No processo deontológico jornalístico, a noticia segue um caminho pré-estabelecido que visa, principalmente ou teoricamente, a divulgar uma matéria que tenha seu valor noticioso e que seja estruturada dentro dos padrões utópicos de representação da realidade "real" (teoria do espelho). No entanto, a notícia transita em uma tríade de limites tênues imbricados (subjetividade-interesse público/ privado - relevância social/institucional) e tem sua noticiabilidade valorizada de acordo com o quanto de tempo e de atenção conquistou. Muitas vezes, segundo Traquina (2005), a forma de tratamento e a abordagem que o jornalista dá à notícia - objetiva ou parcial - são características inerentes e já consolidadas, na ótica dos cidadãos, do jornalismo atual.

A notícia terá o seu grau de projeção e o seu proposto valor social, de acordo com os aspectos políticos e econômicos que Nelson Traquina (2005, p. 165) cita no contexto da teoria de ação política:

O papel determinante dos proprietários dos media e a ligação estreita entre a classe capitalista, as elites e os produtores mediáticos; b) a existência de um acordo entre personalidades da classe dominante e produtores mediáticos; c) a total concordância entre o produto jornalístico e os interesses dos proprietários da elite.

E seguem, ainda, conceitos balizados por diversas teorias do jornalismo, nas quais se inclui que ela é a estrutura que sustenta o fomento capitalista e que "seu conteúdo [em uma visão de esquerda] é imposto aos jornalistas pelos dirigentes das empresas de comunicação e condicionado pela estrutura econômica" (CHOMSKY apud PENA, 2006, p. 147). O fato de poucos serem donos de muitos grupos midiáticos potencializa a influência na formação da opinião pública e faz com que os veículos ordenem as relações sociais.

A fim de explicitar a projeção da visibilidade noticiosa do embate entre ambas emissoras, em quase duas décadas, realizou-se um levantamento quantitativo no jornal diário Folha de São Paulo (periódico de abrangência nacional e de maior tiragem de exemplares) do número de matérias publicadas que tiveram como tema, diretamente ou não, o embate midiático da Rede Globo e Rede Record (Gráfico 1).

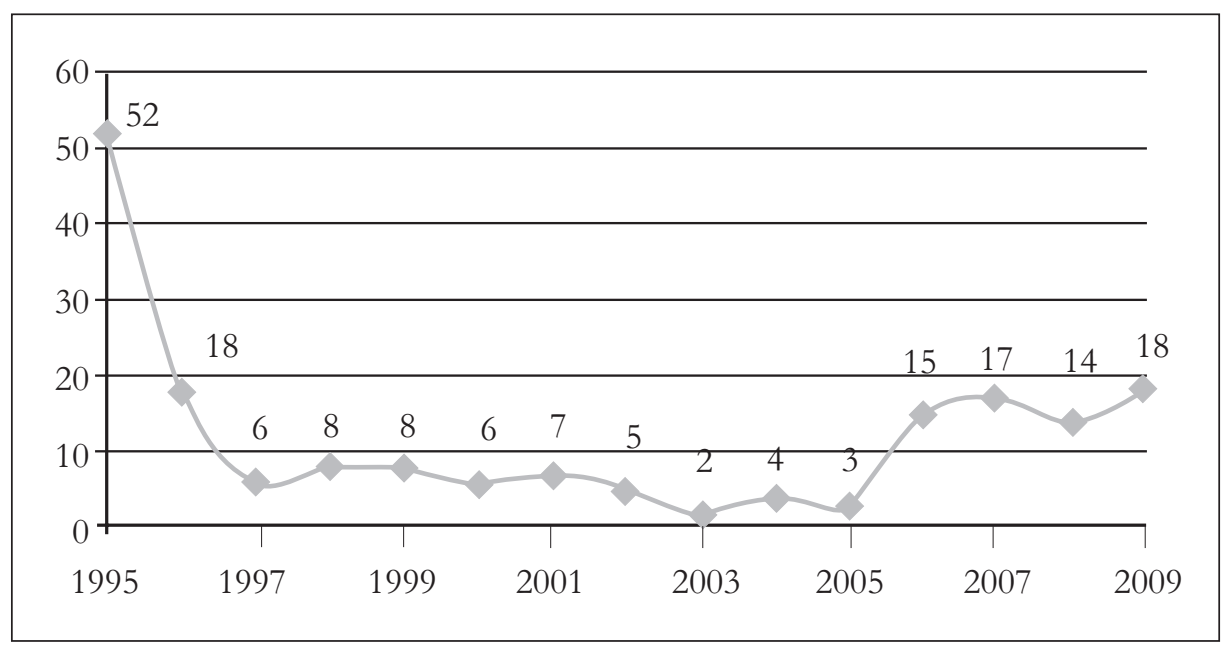

Gráfico 1 - Número de inserções/ano, no Jornal Folha de São Paulo, tematizando o embate midiático

Fonte: Folha de São Paulo (1995-2009). 
Desta forma, observam-se pontos expoentes no gráfico (anos 1995, 1996, 2006, 2007, 2008 e 2009) que explicam o contexto sociopolítico em que se encontravam as adversárias e como foi o tratamento dado pela mídia.

Os anos de 1995-1996 foram marcados pelo atitude do pastor Sérgio Von Helder, que chutou e socou a imagem da padroeira do Brasil, em seu dia oficial, no programa litúrgico Despertar da Fé, e pela reprodução do fato, no dia seguinte, no Jornal Nacional. Globo e Record utilizaram seus meios de comunicação para ataques mútuos posteriores que tiveram a religião como totem na primeira grande disputa midiática.

No mês seguinte, o mesmo telejornal divulgou um vídeo que mostrava Edir Macedo ensinando seus pastores como extorquir dinheiro dos fiéis. Tal comportamento foi veiculado em demasia e teve desdobramentos noticiosos até o ano seguinte em toda a mídia nacional.

No decorrer dos anos, a Rede Record diminuiu seu enfoque na religião neopentecostal e tentou desvincular-se da Igreja Universal. Grandes investimentos foram feitos para obter um crescente índice na audiência. Atores, diretores e técnicos foram contratados da Globo. SBT, Bandeirantes e Rede TV! foram ultrapassadas e, desta forma, nos anos 2006-2009, a emissora da família Marinho retornou à disputa midiático-jurídica a fim de frear o crescimento de audiência adversária.

Um dos ápices do embate pela audiência transcorreu durante o programa diário matutino da Rede Record Hoje em dia, do dia 12 de novembro de 2009. Repórteres de ambas emissoras discutem, ao vivo, a fim de obter em primeira mão explicações do secretário executivo do Ministério das Minas e Energia, Marcio Zimmerman, sobre o apagão ocorrido em quase todo o País. O evento, que transcorreu por quase oito minutos em um ambiente de constrangimento, teve a intermediação via estúdio do apresentador do programa, Celso Zucatelli, que ficou instigando, reiteradas vezes, a repórter a tentar entrevistá-lo, haja vista que a profissional da Globo conseguira prioridade na entrevista que não havia começado:

Repórter da Record (RR): Um só minutinho, por favor, secretário, licença.

Repórter da Globo (RG): (obstrui passagem da repórter).
RR: É, a gente não pode entrar agora. Como você pode ver, o secretário não pode falar nesse exato momento [...]. Alguns assessores impediram a nossa entrevista [...],

Zucatelli (Z): Vamos ouvir o que ele tem para falar. Vê se você consegue falar com ele.

RR: Secretário, por favor...

RG: Venina [repórter da Record], ele está entrando no ar agora, por favor!

RR: Secretário, o que o senhor tem a dizer?

Secretário (S): (mudo).

RG: (obstrui passagem da repórter).

Z: Eu percebo que a entrevista ainda não começou. Vamos tentar conversar com ele mais uma vez?

RR: Secretário, o senhor pode falar com a gente em seguida? O tempo em que está parado, o senhor não pode adiantar para a gente quais são as conclusões?

S: (mudo).

$\mathrm{Z}$ : Eu vou pedir para você insistir mais uma vez. Eu sei que é até chato para você...

RR: É, eu vou tentar mais uma vez [...].

RG: (obstrui passagem da repórter).

RR:Secretário, o senhor pode falar com a gente? (homem obstrui a passagem).

RR: O senhor quem é?

S: Sou assessor do Ministério de Minas e Energia (A).

RR: Por que ele não pode falar com a gente?

A: Porque estava tudo marcado, pré-agendado antes, dele primeiro falar com a Globo, depois falar com vocês. Você saiu do seu link, veio até aqui, invadiu o link da Globo, quis passar por cima [...].

Z: Não tem problema, [...] ele não esta no ar. Isso vai contra a democratização da informação. É uma pena isso [...]. Tudo que a população precisa é informação.

(YOUTUBE, 2009).

Nota-se que, durante a entrevista, o programa tornou-se espetáculo midiático que se utilizou do sensacionalismo e que se transformou em dramatização gratuita, com o intuito, antevisto ou não, de traduzir "uma preocupação com o embaralhamento de fronteiras entre a informação e entretenimento, realidade e ficção" (GOMES, 2008, p. 59). No entanto, o espetáculo televisivo motivado pela audiência em 
primeiro lugar e pelo "tudo que a população precisa é informação”, segundo o apresentador, faz desta sociedade contemporânea uma evolução da descrita por Guy Debord.

O espetacular assume novos horizontes e novos seguidores, uma vez que hoje ele se utiliza da imagem como totem isento de valor e atrações. Segundo Silva (2009), estamos em uma sociedade em que seu capital não é um conjunto de imagens, mas uma relação de competição imagética de autopromoção e de procura pelo tempo alheio. Nesta sociedade do hiperespetáculo, o telespectador segue seu totem em função da qualidade da relação, e não pelo tempo de duração e da admiração. No entanto, nota-se que se troca de canal, mas se mantém o mesmo programa. Muda-se a rede, mas não o sentido.

O novo espetáculo é integral. É democrático. O que antes era fetiche e contemplação utópica, agora passa a ser um sonho possível. O "eu" agora é "o outro". Essa busca factível e passiva se consolida na tela da televisão e é potencializada pelas conjunturas das redes televisivas, que a cada dia se tornam fomentadores dos hiperespectadores, que buscam nos programas o privado vindo a público, o pastiche, o trivial, o banal.

\section{Considerações finais}

O embate midiático entre as duas emissoras de maior audiência atualmente no país, que em suas origens passaram por processos de aquisição duvidosos, "ilegais", faz parte de um processo político-econômico que tem frequência cíclica e que já dura cerca de duas décadas. Essa disputa, hoje, vem tomando vulto maior, haja vista o envolvimento, indireto, de segmentos religiosos neopentecostais na formação opinativa pública, além de estarem em um processo expansivo crescente de efetivo, de poder multimidiático e político, nas bancadas das três esferas. A evolução nesta tríade área vem trazendo isoladas derrotas na audiência da Rede Globo, que alterou diversas vezes sua grade de programação de forma a atender a vários nichos sociais, a grupos mais populares e à demanda tecnológica, política, econômica da cultura de massa.

Essa disputa, para Silva (2007), não é o fim da novela, mas uma novela sem fim, que terá sua sequência em outro capítulo. Os protagonistas talvez mudem de nome e figurino, mas o roteiro e a direção devem permanecer inalterados. O título da matéria será apropriado de valores ideológicos e de sinônimos.

Globo e Record têm em sua origem processos de aquisição protagonistas de um processo de massificação da informação hiperespetacular que objetiva a consolidação ou apropriação da hegemonia midiática - que, hoje, é o cimento social moderno.

\section{Referências}

ALMEIDA, R. A Igreja Universal e seus demônios: um estudo etnográfico. São Paulo: Terceiro Nome, 2009.

AMORIM, A. B. 45 anos de história da Rede Record. São Paulo: Antônio Bellini, 1999.

BORELLI, S.; PRIOLLI, G. (Coord.). A deusa ferida. São Paulo: Summus, 2000.

CASTRO, D. Record estaciona e já não assusta a Globo. Folha de São Paulo, São Paulo, p. E13, 27 nov. 2008.

BRASIL. Constituição (1988). Constituição: República Federativa do Brasil. Brasília, DF: Senado Federal, 1988.

DATAFOLHA. Dossiês: 64\% dos brasileiros se declaram católicos. 05 mai. 2007. Disponívelem: <http://datafolha. folha.uol.com.br/po/ver_po.php?session $=447>$. Acesso em: 21 ago. 2009.

ELIADE, M. O sagrado e o profano. São Paulo: Martins Fontes, 2008.

FERRARI, O. A. Bispo S/A: a Igreja Universal do Reino de Deus e o exercício do poder. 3. ed. São Paulo: Ave-Maria, 2007.

FOLHA DE SÃO PAULO. São Paulo: Folha Online, 1995-2000. Disponível em: <www1.folha.uol.com.br/ $\mathrm{fsp} />$. Acesso em: $16 \mathrm{dez} .2009$.

GOMES, I. O que éjornalismo popular? In: COUTINHO, E.; FILHO, J.; PAIVA, R. Mídia e poder: ideologia, discurso e subjetividade. Rio de Janeiro: Mauad X, 2008. p. 57-79.

GRUPO IBOPE. Acesso gratuito TV Programas SP - semanal. Disponível em: <http://www.almanaqueibope.com.br/asp/busca_resultado.asp $>$. Acesso em: 13 dez. 2009.

HERZ, D. A história secreta da Rede Globo. 13. ed. Porto Alegre: Ortiz, 1989. 
INSTITUTO BRASILEIRO DE GEOGRAFIA E ESTATÍSTICA - IBGE. Censos/Censo_demográfico_2000/população/Brasil/Brasil_religião.zip/ arquivo t1301. Tabela 1.3.1. Disponível em: $<$ http:// www.ibge.gov.br/servidor_arquivos_est/ > . Acesso em: 10 ago. 2009

MATTOS, S. História da televisão brasileira: uma visão econômica, social e política. 3. ed. Petrópolis: Vozes, 2008.

MARIANO, R. Neopentecostais: sociologia do novo pentecostalismo no Brasil. São Paulo: Loyola, 2005.

MARTHE,M.No ar, mais um vice-campeão de audiência. Revista Veja, n. 40, p. 83-92, 2007.

PENA, F. Teoria do jornalismo. São Paulo: Contexto, 2006.

SILVA, J. M. Depois do espetáculo (reflexões sobre a tese 4 de Guy Debord). In: GUTFREIND, C.; SILVA, J. Guy Debord, antes e depois do espetáculo. Porto Alegre: EDIPUCRS, 2007. p. 31-42.

TRAQUINA, N. Teorias do jornalismo. 2. ed. Santa Catarina: Insular, 2005. v. 2.

TROCA de mãos. Revista Veja, n. 1.105, p. 155, nov. 1989.

VALLE,J.E. dos R. Psicologia e experiência religiosa. São Paulo: Loyola, 1998.

YOUTUBE. Barraco da repórter da Globo. Disponível em: $<$ http://www.youtube.com/watch?v $=$ FwEU20soug8 $>$. Acesso em: 10 dez. 2009.

Recebido 09/03/2010

Received: 03/09/2010

Aprovado 17/03/2010

Approved: 03/17/2010 